\title{
The Effect of Binder and Waste Granular Materials (WGM) on the Shear Strength and Shear Resistance of Dredged Marine Soils (DMS)
}

\author{
Mohammad Zawawi Rosman ${ }^{1, a}$ and Chee-Ming Chan ${ }^{1, b}$ \\ ${ }^{1}$ Faculty of Engineering Technology, Universiti Tun Hussein Onn Malaysia, 86400, Parit Raja, Johor.
}

\begin{abstract}
Dredged marine soil (DMS) is considered as weak and soft problematic soil. It is possible to give this type of soil a second life if only its geotechnical properties are improved. Infusing soil with solidification agent is the common practice of soil improvement. This study uses binder and waste granular material (WGM) such as cement, bottom ash (BA) and palm oil clinker (POC). The aforementioned materials are capable to fortify the poor features of the soil. Series numbers of soil bed samples were tested for its shear strength and shear resistance. Test results show that the mentioned soil parameters were corresponded with each other. In short, geo-waste and biomass materials are possible to be reused instead of being discarded.
\end{abstract}

\section{Introduction}

Excavation of dredged marine soil (DMS) in the open channel is considered as dredging. This activity is required to satisfy maintenance improvement work near the shipway. During this process, an abundant amount of DMS was retrieved. In Malaysia, about $300,000 \mathrm{~m}^{3}$ of DMS was gathered and disposed as part of maintenance dredge work [1].

Mostly, DMS consists of high percentage of fines. As the DMS was removed out from the water body, the suspended sediments would cause turbidity [2]. This would result into negative effects toward the marine ecosystem, either in short or long term. In addition, repetitive dredge-dispose routine will also cause monetary complication. The cost of dumping DMS to the designated dumping sites alone could be as high as $20 \%$ of the total operational cost [3]. Both of these problems can be alleviated by considering the beneficial reuse of DMS. One of the beneficial uses of DMS is as reclamation fill.

Naturally, DMS are high in compressibility, high water content, low load bearing capacity and low permeability. If DMS is consider to be reuse as reclamation fill, this cohesive and highly saturated soil would hinder the dissipation of pore water pressure (consolidation) process. Thus, any development built on top of this soil would undergo excessive and nonuniform settlement. This detrimental phenomenon is known as consolidation settlement. However, the aforementioned problem could be resolved by mixing the soil with hydraulic binder and waste granular materials.

Hydraulic binder such as cement is commonly used to stabilize soft and problematic soil. As explained in [4, 5], soil-cement interaction can be generalized into two parts of reaction. Primary reaction occurs when clay was added into a mixture of water and cement. At this stage, the soil would develop initial strength as the cement-hydration products reacted and formed a hardened skeleton. The secondary reaction which is known as pozzolanic reaction was as a result of effect of secondary cementation products. It would then harden by age and further improve the strength of the mixed soil.

In simple term, waste granular material (WGM) is a type of granular soil which originated as waste byproduct from the industrial plant. Among the WGM are bottom ash (BA) and palm oil clinker (POC). BA is a waste residue from the incineration process of coal whereas POC is a waste from the combustion of palm husk and palm shell $[6,7]$. Both of the WGM are likely to be disposed as landfill and it shows that the WGM had affected the environment. In order to overcome the waste management, WGM has been alternately used as soil stabilizer. Some studies [8,9] had highlighted the advantages of using BA and POC as soft soil stabilizer. It shows that soft soil which admixed with WGM is able to improve in strength due to its cementation nature and its frictional resistance.

This study assessed the shear strength and shear resistance of DMS admixed with cement, BA and POC. Numbers of soil bed with various percentages of binder and WGM were tested in accordance to time. Laboratory vane shear and laboratory cone penetration test were used to obtain such required results.

\section{Materials}

2.1 Dredged Marine Soils (DMS)

a,b Corresponding author: mzawawirosman@gmail.com, chan@uthm.edu.my 
The disturbed soil sample was retrieved from Kuala Kedah (Kedah) at the distance of 1.5-2 km from the jetty. Trailing suction hopper dredger was used to collect the soil sample at depth of $8-10 \mathrm{~m}$ from the sea level. Sets of long scoop were used to obtain DMS inside the sedimentation chamber as shown in Figure 1. Then, the soils were transferred into pails for easy handling. On land, the soils were then secured with plastic bags and stored inside large air-tight containers to prevent any loss of moisture. Table 1 shows the physical properties of DMS.

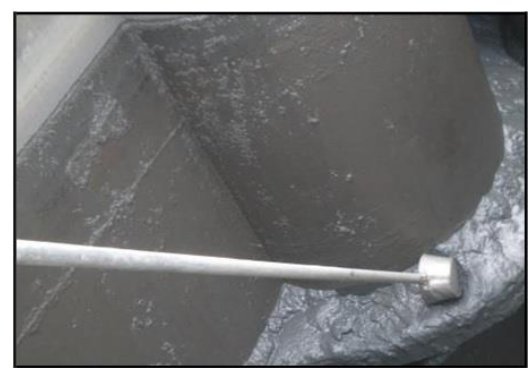

Figure 1. Long scoop was used to obtain the DMS

Table 1. Physical properties of DMS

\begin{tabular}{|c|c|}
\hline \multicolumn{2}{|c|}{ Physical Attributes } \\
\hline $\begin{array}{c}\text { Natural Water Content } \\
\text { (Wi) }\end{array}$ & $91.96 \%$ \\
\hline Plasticity Index (PI) & 16.20 \\
\hline Liquid Limit (LL) & $47.70 \%$ \\
\hline Plastic Limit (PL) & $31.50 \%$ \\
\hline Size Distribution & $\begin{array}{c}\text { Gravel }-1 \%, \text { Silt }-31 \% \\
\text { Sand }-41 \%, \text { Clay }-27 \%\end{array}$ \\
\hline Specific Gravity $\left(\mathrm{G}_{\mathrm{s}}\right)$ & 2.57 \\
\hline $\mathrm{pH}$ & 8.00 \\
\hline
\end{tabular}

\subsection{Binder and Waste Granular Materials (WGM)}

Binder and waste granular materials (WGM) used in this study are cement, bottom ash (BA) and palm oil clinker (POC) respectively. Cement powder was manufactured, whereas BA and POC were retrieved from industrial plant in Johor. The obtained large chunks of WGM were then grounded and sieved passing $2 \mathrm{~mm}$ aperture.

In Figure 2, particle size distribution of DMS, BA and POC were shown. Clearly, DMS is finer than the WGM. POC was proven to be coarser than BA. Theoretically, it would enhance the consolidation process due to the large void of a coarse grained soil.

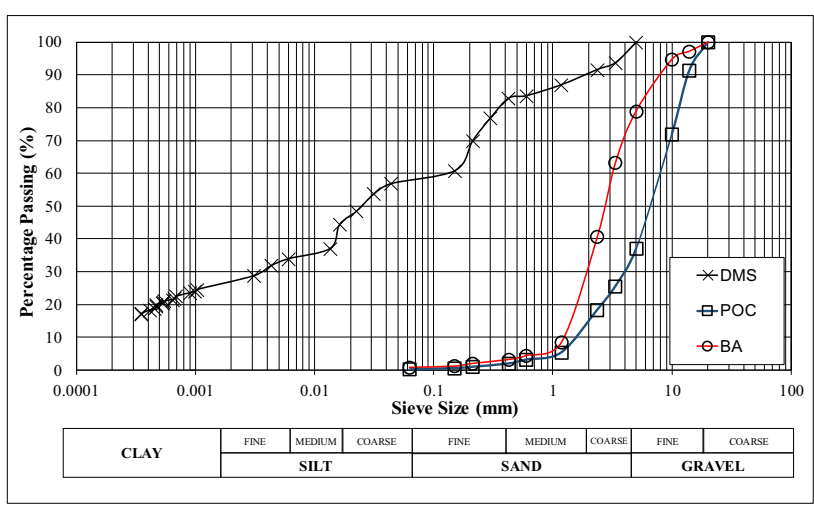

Figure 2. Particle size distribution

\section{Methods}

\subsection{Sample Preparation}

DMS were admixed with cement, BA and POC. Percentages of cement and WGM (BA or POC) were determined by the dry weight of soil and can be illustrated in soil phase diagram. Generally, the soil phase diagram consists of air, water and soil phases. Each phase indicates mass of each component such as mass of water (MW), mass of soil (MS), mass of cement (MW) and mass of WGM (MWGM). In this study, DMS is a highly saturated soil. Therefore, major phases inherent in DMS would be water and soil. Due to the fine-grained nature of DMS, the air phase was negligible since there is a small amount of air inside the void.
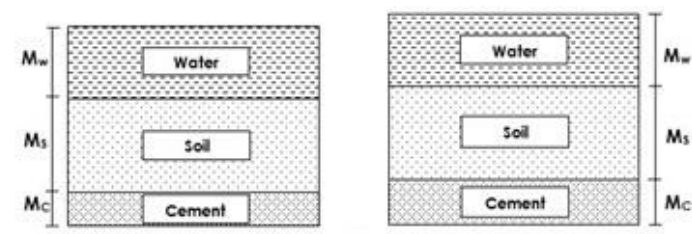

(a)
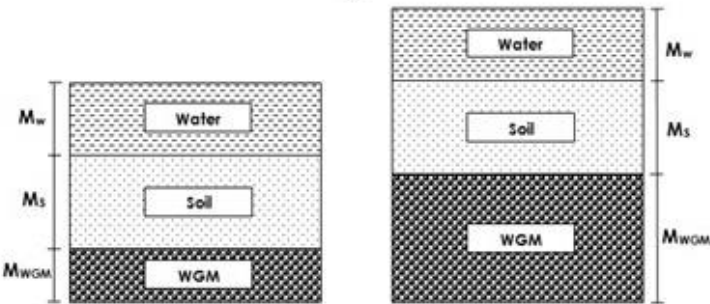

(b)

Figure 3. Soil phase diagram: (a) Cement admixed soil and (b) Granular admixed soil (shown in per-positioned ratio)

In Figure 3(a), the percentages of cement admixed soil are $10 \%$ and $20 \%$ by the dry weight of soil. Meanwhile in Figure 3(b), the percentages of WGM are $50 \%$ and $150 \%$ by the dry weight of soil. Each of percentage denotes the minimum and maximum dosage for each admixed soil. Since WGM is less cementitious than cement, higher values of WGM were purposely selected in order to compare the cementation effect. 


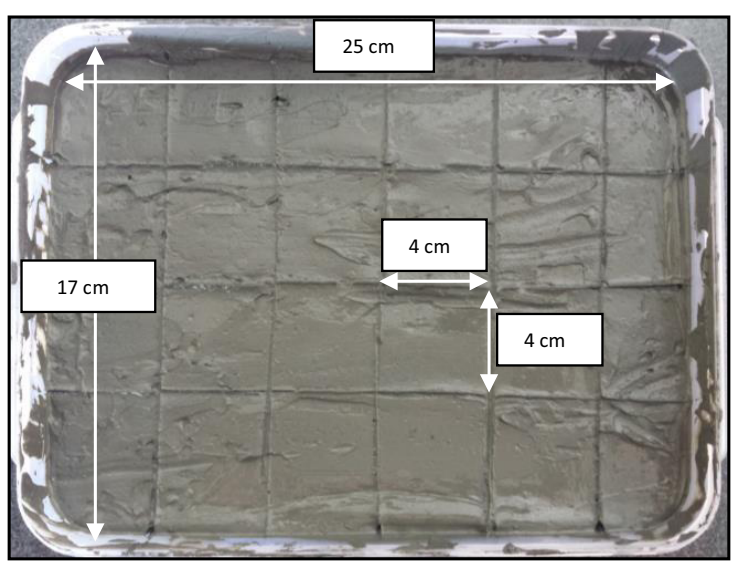

Figure 4. Gridline of soil bed samples

All of the soil bed preparation was based on [10] where the admixed soil was poured inside $7.5 \mathrm{~cm} \mathrm{x} 17 \mathrm{~cm}$ x $25 \mathrm{~cm}$ plastic containers as illustrated in Figure 4. Approximately three (3) layers of soil with the total sample depth of $5 \mathrm{~cm}$ were deposited. By tapping the plastic container, any trapped air bubble inside could be removed. Laboratory vane shear and laboratory cone penetration tests were conducted up until 28 days with the time interval of $0,1,2,3,4,5,6,7,14$ and 28 days. Square grids of $4 \mathrm{~cm} \times 4 \mathrm{~cm}$ were outlined in order to prevent any disturbance to the neighbouring soils.

\subsection{Laboratory Vane Shear Test}

Laboratory vane shear test was used to determine the value of undrained shear strength $(\mathrm{Cu})$ of soil in accordance to the standard [11]. As in Figure 5, the dimension of the vane used in this study is $12.7 \mathrm{~mm} \mathrm{x}$ $12.7 \mathrm{~mm}$. There are four torsion springs provided, ranging from the spring number 1 to 4 . The selection of torsion spring was based on the type of soil and its physical strength. For instance, firm (stiffest) soil will be using the spring number 1 and as for the softest (weak) soil will be using the spring number 4 .

The vane was later inserted in the middle depth of the soil to obtain the fair value of $\mathrm{Cu}$. As the handle start to operate, torque was applied to the vane. The maximum deflection angle was observed and recorded. The $\mathrm{Cu}$ value was calculated using the formula stated in the standard.

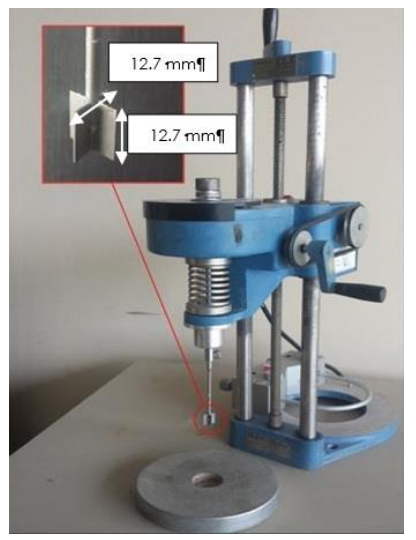

Figure 5. Laboratory vane shear apparatus

\subsection{Laboratory Cone Penetration Test}

Generally, cone penetration test was used as a method to obtain the liquid limit of soil. In this study, such result of the cone penetration depth (DP) was obtained. The overall procedure was based on standard [11]. Figure 6 shows the laboratory cone penetration apparatus. The cone is weighed about 80 grams, with angle of $30^{\circ}$ and the height of $35 \mathrm{~mm}$. By using the similar square grid and rest period intervals, the tip of the cone was lowered down as it barely touches the soil bed's surface. As the cone was released, it

would then penetrate the soil within 5 seconds of time. Values of DP were monitored and recorded throughout the interval periods. DP notes the shear resistance of the soil mix.

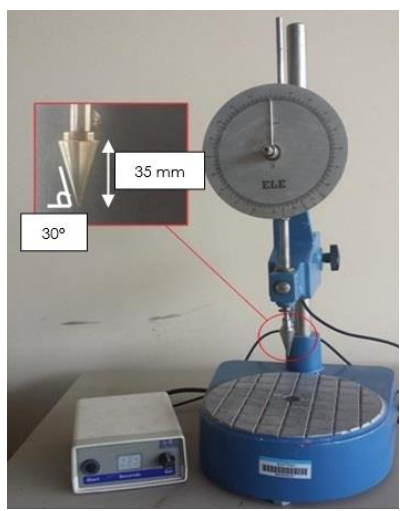

Figure 6. Laboratory cone penetration apparatus

\section{Results}

\subsection{Shear Strength}

The obtained values of undrained shear strength $(\mathrm{Cu})$ were plotted against time as shown in Figure 7 (a \& b). There are two graphs, namely cement admixed sample and WGM admixed sample. Both of the graphs are distinguish from one to another in order to compare the effect of binder and waste granular infused soil.

Note that the $\mathrm{Cu}$ value of the untreated soil is negligible since none torsion was detected. This is primarily due to the liquefied nature of DMS which contain high value of moisture. The natural water content for this particular DMS is almost twice the liquid limit (Wi/LL). Even in [12] findings, Wi/LL up till $1.76 \mathrm{LL}$ had resulted with none $\mathrm{C}_{\mathrm{u}}$ value. 

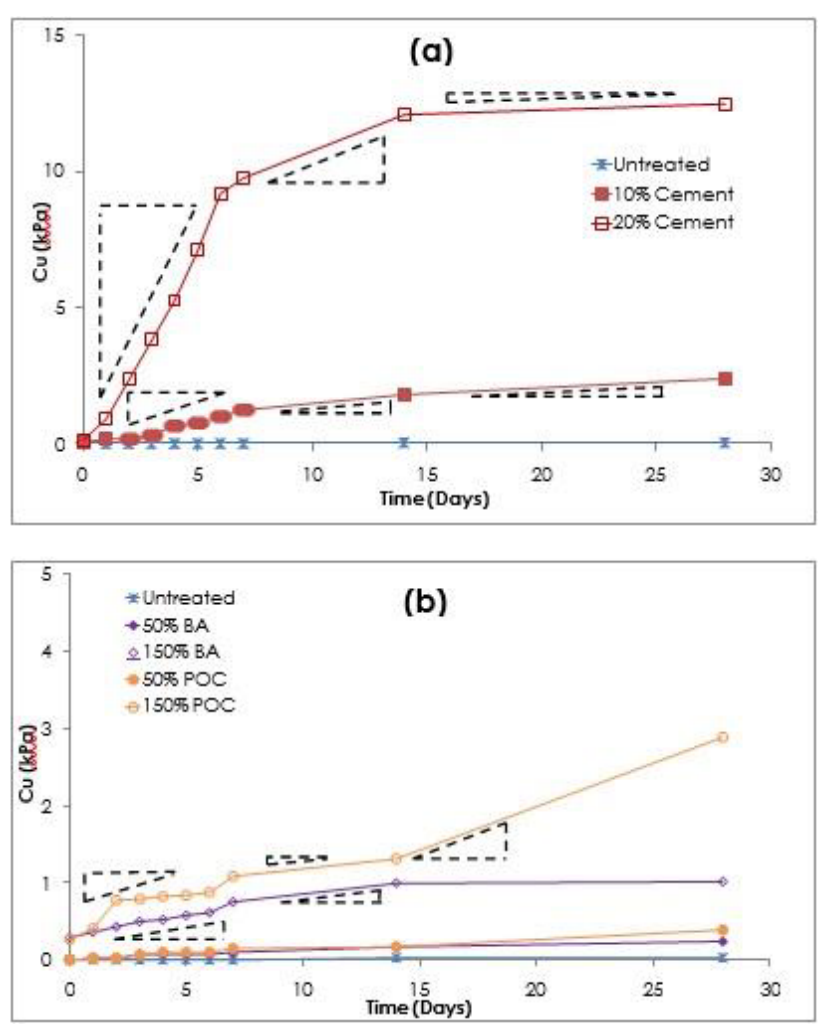

Figure 7. $\mathrm{Cu}$ - Time plots: (a) Cement admixed soil and (b) WGM admixed soil

For cement admixed soil, the $\mathrm{Cu}$ values at 28 days for both percentages are ranging from 2-12 $\mathrm{kPa}$. However, the $\mathrm{Cu}$ values at 28 days for WGM admixed soil are in the range of $0-3 \mathrm{kPa}$. Obviously, the cement admixed soil had improved the untreated soil effectively than the WGM admixed soil.

In term of percentages, $20 \%$ of cement shows greater $\mathrm{Cu}$ value than $10 \%$ of cement. $50 \%$ of WGM had small effect of strength whereas $150 \%$ of WGM shows fair increase of strength on the untreated soil. Regardless with the high percentages of WGM, the effect of strength does not outmatch with the cemented soil.

Illustrations of strength increase gradient (dashed line triangles) were shown in both graphs. It is noticeable that in term of time, the highest gradient can be observed up until 7 days. This shows that the shear strength was developed significantly up until 7 days. After 7 days, the $\mathrm{Cu}$ value is still increasing but would be that less significant. Note that the $150 \%$ of POC have high value of $\mathrm{Cu}$ at 28 days than $150 \%$ of BA. $150 \%$ of POC exhibit great increase of shear strength after 7 days. It is possibly due to the cementation effect of POC that takes in greatly beyond initial 14 days.

\subsection{Shear Resistance}

Figure 8 displayed the graphs of penetration depth (DP) against time. Different graphs were plotted to observe the effect of cement and WGM addition to the soil. High value of $\mathrm{Dp}$ shows that the soil has less shear resistance against the falling cone.
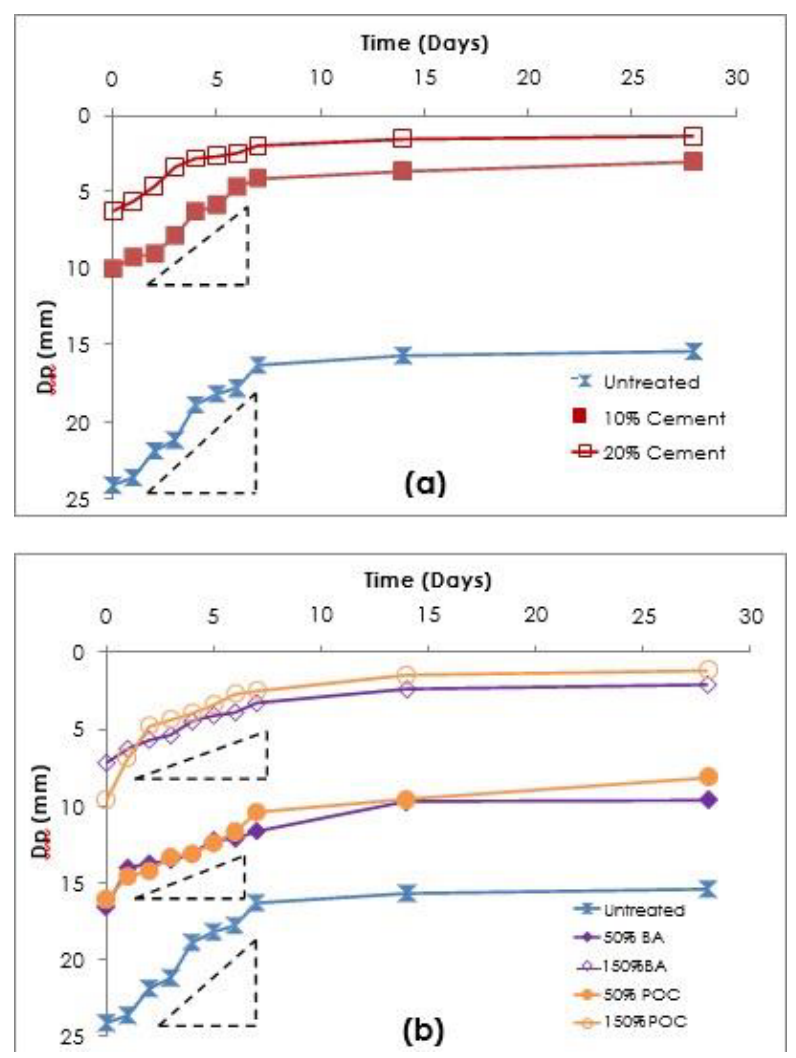

Figure 8. $D_{P}$ - Time plot: (a) Cement admixed soil and (b) WGM admixed soil

The untreated soil was tested for its $\mathrm{Dp}$ value as controlled sample. The Dp values at 28 days for untreated soil is $15 \mathrm{~mm}$. As for Dp values at 28 days for cemented soil are in the range of 1-3 $\mathrm{mm}$. Meanwhile, the Dp values at 28 days for WGM admixed soil are in the range of 1-9 mm. Clearly, cement was able to increase the shear resistance of the untreated soil than WGM admixed soil.

By percentages, the trend line for $10 \%$ and $20 \%$ of cement are almost parallel to each other. Higher dosage of cement gives a great shear resistance. Despite the different type of WGM used, $50 \%$ and $150 \%$ of BA and POC shows a quite aligned trend line to each other. It proves that the shear resistance for both percentages is quite similar. However, note that the Dp values at 28 days between both percentages of cement and $150 \%$ of WGM are alike. It is probably due to the higher content of coarse and granular materials in the soil which contributes to the great shear resistance.

In accordance to time, the gradient of resistance displayed in both graphs had shown significant increase at the initial period of 7 days. Throughout the time, the admixed soil would develop shear resistance but that less remarkable.

\section{3 $C_{u}{ }^{\prime}-D_{p}$ Relationships}

Both parameter of shear strength ratio ( $\left.\mathrm{Cu}^{\prime}\right)$ and penetration depth ratio (DP') were plotted interrelate with each other in Figure 9. The value of $\mathrm{Cu}^{\prime}$ is the ratio of obtained $\mathrm{Cu}$ over the known maximum $\mathrm{Cu}$ [13]. The DP' is the ratio between obtained DP and the height of cone. 

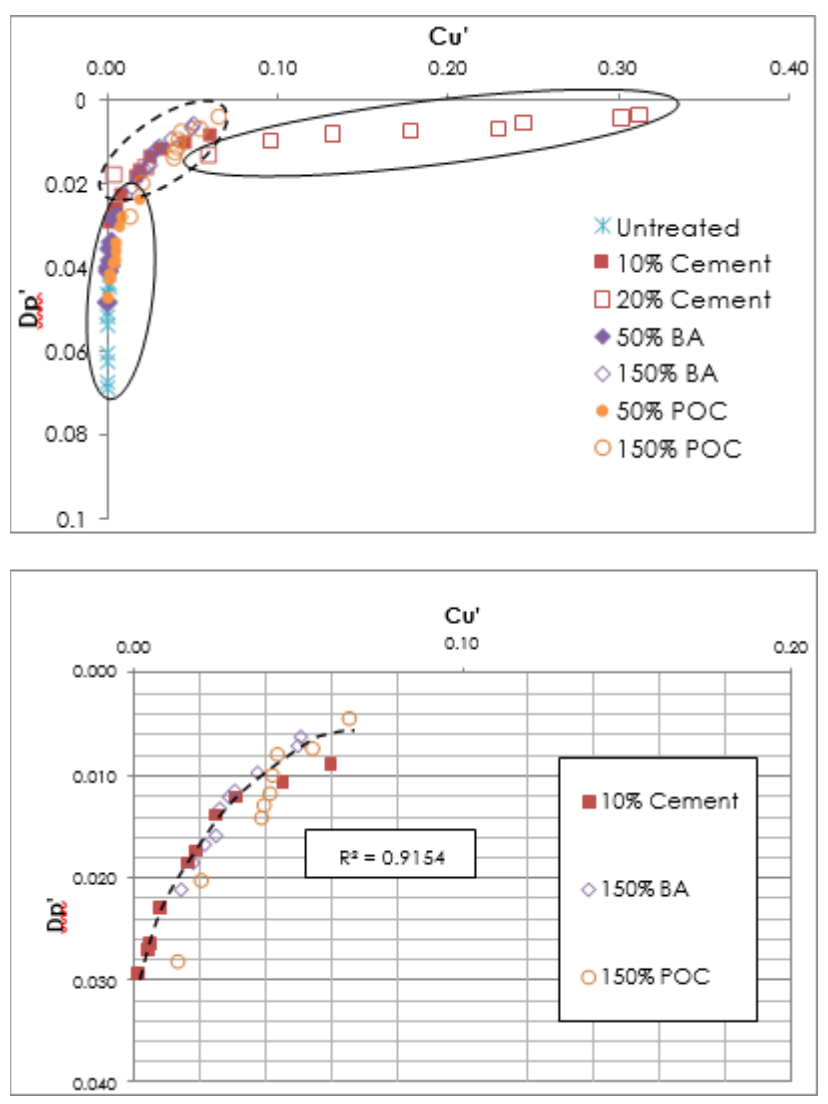

Figure 9. CU' - DP' correlation plot

As highlighted (circled line) in Figure 9(a), the untreated and $50 \%$ of WGM admixed soil had formed together closely in the DP' range of $0.02-0.07$. Also, observed that the packed crowd gives the CU' value up till 0.01 . The $20 \%$ cemented soil was also highlighted and it's shown that the data plot was almost stable at the C' and D' range of 0-0.32 and 0-0.02. The highlighted plots indicate that the $50 \%$ of WGM and $20 \%$ of cement have least and excessive gain in strength and resistance respectively. Therefore, the correlation data was considered less significant and excluded.

New graph plot in Figure 9(b) had displayed the focused data set of $150 \%$ WGM and $10 \%$ cement admixed soil. The new data was in range of $\mathrm{Cu}^{\prime}<0.01$ and $\mathrm{DP}^{\prime}<0.004$. Based on the plotted regression fit line, the value of $\mathrm{R}^{2}$ is 0.9154 . It proves that the $\mathrm{Cu}^{\prime}$ and $\mathrm{DP}$ ' values were compatible. As the shear strength increase, the soil becomes more resistant against shear and vice versa. Note that the $150 \%$ of WGM and $10 \%$ of cement admixed soil contributes to the fair correlated data. Both of it were suggested to be able to provide such good strength and resistance.

\section{Conclusions}

The beneficial uses of DMS can be considered if certain improvement on its geotechnical properties were made. It is achievable by suggesting the use of binder and WGM such as cement, bottom ash (BA) and palm oil clinker (POC) respectively. This study underlines the possible reutilization of the waste material (DMS, WGM) by evaluating its enhanced feature after admixed together. Series of laboratory vane shear and cone penetration tests on binder and WGM admixed soil were conducted. Overall findings are summarized as follows;

1. Based on the shear strength at 28 days, cement admixed soil shows great improvement in strength rather than WGM admixed soil.

2. WGM admixed soil was able to improved strength along period of time but shows less significant effect compared to the cemented soil.

3. Suggested that WGM and cement should be mixed together to elevate the strength.

4. Cemented soil and $150 \%$ of WGM admixed soil gives greater shear resistance than others. Cement infused soil improves its resistance due to the hardening effect pozzolanic reaction. Meanwhile, the WGM admixed soil inherent almost similar resistance as cemented soil due to the high content of granular materials.

5. Shear strength and shear resistance were developed significantly during the rest period of 7 days.

6. The shear strength and resistance of the admixed soil were proven to correspond with each other. Increasing shear strength shows better resistance and vice versa.

\section{Acknowledgement}

The authors gratefully acknowledged the financial support provided by Centre of Graduate Studies (CGS) UTHM.

\section{References}

1. W. S. Wan Salim, N. A. Mohd Noor, M. F. Arshad, N. Wahid, S. Mohd Salleh, $2^{\text {nd }}$ International Conference on Biotechnology and Environment Management 42, 25-29 (2012)

2. C. A. Schipper, Assessment of Effects of Chemical Contaminants in Dredged Material on Marine Ecosystems and Human Health, Ph.D, Wageningen University (2009)

3. A. Azhar, C-M. Chan, A. T. Abdul Karim, Electron J Geotech Eng 19, 8797-8805 (2014)

4. M-H. Ho, C-M. Chan, Int J Civ Env Str Con Arch Eng 5(2), 6-13 (2011)

5. M. Kitazume, M. Terashi, The Deep Mixing Method (2013)

6. H. Gullu, Soils Found 54(3), 462-477 (2014)

7. M. E. Rahman, M. Leblouba, Pertanika 22(2), 627636 (2014)

8. Y. T. Kim, J. Ahn, W. J. Han, M. A. Gabr, J Mater Eng 22, 539-544 (2010)

9. R. Robani, C-M. Chan, International Conference on Engineering and Education 1-4 (2009)

10. C-M. Chan, Electron J Geotech Eng 20, 5847-5856 (2015)

11. British Standard, British Standard Method of Test for Civil Engineering Purposes BS1377 (1990)

12. K. H. Head, Permeability, Shear Strength and Compressibility Tests (1982) 